Whitty, M.T. (2008). Liberating or debilitating? An examination of romantic relationships, sexual relationships and friendships on the Net. Computers in Human Behavior, 24, 1837-1850.

\title{
Liberating or debilitating? An examination of romantic relationships, sexual relationships, and friendships on the Net
}

\section{Monica T. Whitty}

University of Nottingham Trent University, UK

Ever since the beginnings of the internet researchers have questioned its utility in developing and maintaining psychological healthy romantic and sexual relations. Advocates of the Social Presence Theory and Media Richness Theory purport that in leaner media individuals can be quite aggressive towards one another (e.g., in the form of flaming). In contrast, others believe that the lack of traditional cues in CMC can in fact be overcome and instead lead to more personal, intimate relationships. As this paper will demonstrate, when we consider how beneficial it is to form relationships online we also need to consider individuals' characteristics (e.g., personality characteristics, physical attractiveness), the amount of time people spend online, the duration of online relationships, and how these relationships effect individuals' offline activities and relationships. Overall, the view here is that online relationships can be empowering for many people; that is, cyberspace provides a unique environment for people to experience and learn about relationships and sexuality. 


\section{Liberating or debilitating? An examination of romantic relationships, sexual relationships and friendships on the Net}

\section{Introduction}

Over the years there has been much debate as to whether online relating can be liberating or debilitating. Those on the negative side argue that online relationships or what are also often referred to as 'weak' ties are not psychologically beneficial, and take important time away from more psychologically healthy offline relationships. Those who take the more positive stance do so because they believe that the internet provides a space for people to feel freer to express themselves without the usual harsh judgement that can be experienced in face-to-face settings. Of course, both sides have there merit and the debate should not be bifurcated. This paper will highlight the pros and cons of online relating. The view taken here, however, is that in many ways cyberspace has created new opportunities for people to feel empowered and has opened up new and fulfilling opportunities to relate to others.

To begin with this paper outlines early theories (which are still embraced by some theorists today) that contend that online relating can be an impersonal and negative experience. These theories emphasise what is lacking online compared to face-to-face settings.

\section{Online relating: Theories that emphasize the negative aspects}

\subsection{Social Presence Theory and Social Context Cues Theory}


'Social Presence Theory' and 'Social Context Cues Theory' although first devised to explain interactions via teleconferencing, were two of the first theories to be applied to CMC (Computer mediated communication). These theories point out that online, due to fewer non-verbal and paralinguistic cues, there is an extremely low feeling of social presence; that is, an individual's self-perception is reduced and deindividuation is encouraged. Those who have applied this theory have argued that as social presence declines communication becomes more impersonal (Hiltz, Johnson, and Turoff, 1986; Short, Williams, and Christie, 1976; Sproull and Kiesler, 1986). In the absence of typical social context cues, it is said that communication can become increasingly uninhibited and aggressive (e.g., as evident in flaming). In contrast, these theorists argued that an increase in the amount of personal information available will lead to greater positive regard. According to this view, online relating is a more negative and impersonal experience compared to face-to-face. Cyberspace is a space which fosters deceit, abusive and sometime even harassment. As will be highlighted in this chapter, empirical evidence supports some of these theorists' claims.

\subsection{Media Richness Theory}

'Media Richness Theory' takes a similar stance to 'Social Presence Theory' and 'Social Context Cues Theory' in that it examines what CMC lacks compared to face-to-face. This theory contends that individuals are driven to overcome equivocality and uncertainty. Media Richness Theory was originally applied to communication within organisations but has since been applied to other types of relationships. Those who applied it to organisations have suggested that different types of media typically work better for certain tasks. As explained by Daft and Lengel (1986): 
Information richness is defined as the ability of information to change understanding within a time interval. Communication transactions that can overcome different frames of reference or clarify ambiguous issues to change understanding in a timely manner are considered rich. Communications that require a long time to enable understanding or that cannot overcome different perspectives are lower in richness. (p. 560)

The types of criteria that Daft and Lengel (1986) used to define media richness include: a) availability of instant feedback; b) capacity of the medium to transmit multiple cues; c) the use of 'natural language', and d) the personal focus of the medium. According to this theory, face-to-face communication is the richest type of media as is provides immediate feedback and utilises more channels. In contrast, CMC is far less rich as it lacks many of the important features of face-to-face and phone communication. In line with the theories described above, Media Richness Theory suggests that online relating can be far less personal than face-to-face.

\section{Online relating: Theories that emphasize the positive aspects}

Not all theorists believe that leaner media provides an impoverished environment (see Whitty and Carr 2006a for a more in-depth discussion). For example, Suler (2004) and Joinson (2001) have argued that people can be more honest and open about themselves in cyberspace. Similarly, Walther, Slovacek and Tidwell (2001) have argued that with time many of the problems associated with the lack of cues online can be overcome. McKenna and colleagues have proposed that the lack of social presence provides individuals with more opportunities to present aspects of themselves that they do not feel comfortable with displaying in ordinary face-to-face 
conversations (McKenna \& Bargh, 1998, 2000; McKenna, Green, \& Gleason, 2002). Whitty (2003a, 2004) has found that individuals are able to flirt online by substituting translating traditional offline non-verbal cues into text. This paper now turns to examine each of these theorists' claims in more detail. As will be elucidated, these theorists do note some of the negative features of online relating, however, their emphasis is on the more positive and empowering aspects.

\section{1 'Disinhibition effect'}

The 'disinhibition effect' purports that online communication is a doubleedged sword. This effect explained by Suler (2004), occurs when people are able to be more anonymous, which is typically more achievable in online settings than in faceto-face. According to some theorists, when one is more anonymous they feel freer to be more emotionally honest and open and self-disclose more personal information about themselves (Joinson, 2001). This can feel liberating and empowering. The most liberating form of 'disinhibiton' Suler (2004) refers to as 'Benign disinhibition'. This is where people reveal secrets, emotions or their fears. Moreover, they sometimes carry out unusual acts of kindness or generosity.

Not all self-disclosure is empowering. Suler (2004) has argued that sometimes people online are extremely rude or angry. Some will seek out material online that they would not have otherwise have sought out (e.g., violent pornography). Suler names this 'toxic disinhibition'.

\subsection{Hyperpersonal Theory}

Walther et al.'s (2001) 'hyperpersonal theory' has garnered enthusiastic support. 'Hyperpersonal Theory' explains that the problems associated with an 
absence of social cues and social presence online can be overcome. Moreover, people can potentially develop closer relationships more quickly in an online setting. As Walther et al. (2001) state: “CMC users sometimes experience intimacy, affection, and interpersonal assessments of their partners that exceed those occurring in parallel FTF activities or alternative CMC contexts" (p. 109). Net friends and lovers can sometimes offer greater emotional support and empathy compared to offline social networks.

Walther and his colleagues (Walther, 1996; Walther et al., 2001) have explained that people can be quite strategic with their self presentations. On the internet individuals can often take their time at deciding what to communicate (especially in asynchronous forms of communication, such as email). This means that they have time to reflect on what they are trying to communicate and how they present themselves.

When a person has time to decide how to present themselves and are visually anonymous, they are able to create a false or exaggerated depiction of who they really are. Often individuals will elect to present themselves in the most positive light. Being strategic can lead to more intimate and close relationships. However, in turn, it can also lead to idealisation. Seeing someone for better than who they really are is not always the most psychologically healthy way to relate.

It is critical to understand, according to this hyperpersonal communication framework, displays of online affiliative behaviours depend on whether the individual anticipates a long-term or short-term commitment with their online partner. Moreover, the dynamics change if a real image is presented to the person one is communicating with. Walther et al. (2001) found that the presence of a photograph prior to and during CMC had a positive effect on intimacy/affection and social attractiveness for short- 
term CMC partners. Moreover, CMC partners who met online felt less intimacy/affection and social attraction once a photograph was introduced compared to individuals with long-term CMC partners who never saw each other's picture. What this suggests is that when we consider how friendly, liberating, or empowering online relating might be we need to not only account of the types of cues present, but we also need to be mindful that the dynamics can alter depending on when certain cues are presented as well as how individuals intend to progress the relationship.

\subsection{Presenting the 'true' self}

Another very appealing aspect of online relating is that some online environments present individuals with unique opportunities to reveal private details that they would typically feel uncomfortable revealing in everyday face-to-face interactions (e.g., McKenna \& Bargh, 1998, 2000; McKenna et al., 2002). Drawing from personality theorists, such as Rogers (1951) work on the 'true' self, McKenna et al. (2002) reasoned that the internet provides a safer space to disclose 'core' aspects about one's self. Results from their online survey research found that individuals who are more likely to express their true self online consider these relationships to be more identity-important. Hence, while the internet is not necessarily empowering for all individuals, McKenna et al. (2002) found that forming relationships in newsgroup was a positive experience especially for socially anxious and lonely individuals who find it difficult expressing themselves in face-to-face situations.

\subsection{Playing in cyberspace}

Whitty (2003a; Whitty \& Carr, 2006) has also developed a theory which 
contends that relating in cyberspace can be a liberating experience for many individuals. She argues that people often feel freer online compared to face-toface, to flirt, express themselves and engage in sexual activities. Whitty suggests that cyberspace can also feel like a more fun, creative and therapeutic space compared to the offline world.

In devising her theory on relating in cyberspace, Whitty has drawn from object relations theory. In particular (Whitty, 2003a; Whitty \& Carr, 2006) has focused on Winnicott's (1971/1997) contributions to a psychoanalytic perspective of play and considered how these notions might relate to online interactions. It is important to note that although play might seem more relevant to speak about in regards to children's interactions, Winnicott (1971/1997) stated that "Whatever I say about children playing really applies to adults as well” (p. 40). Whitty (2003a) concurs and has written in detail about how individuals might 'play' at love on the internet.

Two aspects ofWinnicott's (1971/1997) work have been taken up by Whitty in her theorizing about online relationships; these are the notions of 'potential space' and 'transitional objects'. Although Winnicott originally used these terms to explain the infant/mother relationship later on he recognised they could be applied to other types of relationships.

As Whitty reports in previous work (see Whitty, 2003a; Whitty \& Carr, 2006), Winnicott (1971/1997) understood 'potential spaces' to be spaces where connections are maintained between an external world and an internal conception of self; the space between the subject and object. According to Winnicott, potential space is the place where play takes place and creativity becomes 
possible. As Winnicott (1971/1997) once wrote, potential space "is outside the individual, but it is not the external world. . Into this play area the child gathers objects or phenomena from external reality and uses these in the services of. . inner or personal reality". (p. 51)

As also outlined in Whitty's (2003a) paper, Winnicott also employed the term 'transitional objects' in his theorising about play. He observed that infants often become fond of a special object, such as a teddy bear, a doll or a blanket, as if addicted to this object. The infant develops an attachment to this object, and might suck the object, or suck their thumb or fingers while holding the object. This object Winnicott named the 'transitional object', or the 'not-me' object. What he means by the 'transitional object' in the case of the child sucking a blanket or some other object is that it is an object that is not the breast but that treating it as such allows the infant to make a distinction between the 'me' and the 'not-me'. In respect to play, Winnicott (1971/1997) asserted that "when we witness an infant's employment of a transitional object, the first not-me possession, we are witnessing both the child's first use of a symbol and the first experience of play". (p. 96)

In line with Winnicott's theoretical conception of play, Whitty (2003a) has argued that cyberspace can be understood as potential space - a space which is not quite real and not complete fantasy. A space which consists of transitional objects (e.g., the computers, monitors, keyboards and so forth). Whitty (2003a) has stated that:

Cyberspace is perhaps a space somewhere outside the individual, but is still not the external world. The participants, the computers, monitors, keyboards, mice, software, modems, text, cables, telephone lines, and so 
forth all occupy this potential space; this space between the 'real individuals' and the 'fantasy individuals'. Indeed the web might be conceptualized as a potential playground. (p. 349)

According to Whitty, cyberspace presents more opportunities than the offline world to be playful. Individuals can experiment with presentations of self. For instance, some might choose to recreate a more attractive body to represent themselves in various spaces online. Moreover, people can theoretically feel safer to flirt and form relation-ships on the internet. This is because the space does not seem as real as offline and so rejection can be easier to cope with. This can be a very empowering experience for individuals, especially those who have been unsuccessful at developing offline relationships. As Whitty (2003a) states:

Flirting is a type of play that can occur in this potential space - cyberspace. Playing at love on the Internet, although synonymous in some ways with offline flirting, is characterized here as a unique activity that is a form of play. There is greater opportunity online for fantasy than there is offline. Online participants can inhabit any body they desire, whether that is a youthful body, an attractive body or even a body of the opposite sex. . . Moreover, the participant can invent what their fantasy partner looks like, feels like, and feels about them. Participants can fantasize that they are attracted to others, and, in turn, others are attracted to them. (p. 349) Turkle (1995) has made a similar assessment to what has been described above. In her view about MUDs players, Turkle suggested that "the computer can be similarly experienced as an object on the border between self and not-self. . 
People are able to see themselves in the computer. The machine can seem a second self" (p. 30). Indeed, we invest emotion toward these objects and, as suggested, these objects can leave a trace within us and serve as psychic keys to unlock emotions. In the case of cyberspace this can happen even before we turn on the computer or log onto the internet.

Like the other theories described above, Whitty (2003a) has emphasised the positive aspects of cyber-relating. However, in agreement with previous theorists she has recognized the dark sides of forming relationships on the Net (see Whitty, 2007a; Whitty \& Carr, 2005). Akin to Walther et al. (2001), she believes that idealisation can occur in cyberspace. Whitty contends that it is psychologically unhealthy for people to stray too far into the fantasy side of the online world - this could lead to relationships that might never live up to expectations if taken into the offline world or alternatively it might lead to cyberinfidelities.

\section{Empirical support for debilitating online relationships}

Although this paper is arguing that there are more positive than negative outcomes in respect to online relating, it is nonetheless important to present a balanced perspective. This paper will now move to consider how online relating might on occasion be debilitating, before providing the counterview of how it might be positive and liberating.

\subsection{Can the internet cause someone to become lonely?}

The first study to raise the alarm about online relationships was conducted by Kraut and his colleagues (1998). In their HomeNet Study, Kraut et al. provided 
households who had never accessed the internet, a computer, a free telephone line, and free access to the internet. During the course of the study they tracked changes in psychological states. They found that greater use of the internet was associated with negative effects on an individual, such as decreases in the size of one's social circle, and increases in depression and loneliness. They argued that this was because internet usage was taking up time that could be better used for more psychologically beneficial interactions offline; that is, that online friendships were weaker and less healthy than offline friendships. As this paper will examine in detail later, these results were later challenged not other by other theorists, but also by Kraut and his colleagues.

\subsection{Excessive use of the internet}

The problems that individuals encounter with relating on the internet might be explained more accurately by considering how people use this space to develop relationships and how much time they spend on it relating to people. While researchers have found that exploring sexuality online can be a positive experience (as detailed later in this paper) it has been found that it is not healthy for those who use the internet excessively to seek out sexual interactions (e.g., Cooper, Delmonico, \& Burg, 2000; Daneback, Ross, \& Månsson, 2006; Griffiths, 1999, 2000; Young, 1998, 1999).

Griffiths $(1999,2000)$ and Young $(1998,2000)$ have written extensively on the topic of internet addiction, claiming that some people can be addicted to online sex and forming relationships on the Net. Researchers have found support for their claims. In a revealing study, Schneider (2000) found that cybersex addiction was a major contributing factor to separation and divorce. Moreover, this study found 
that about half $(52 \%)$ of cybersex users had lost interest in relational sex. Importantly, however, Griffiths has pointed out that many excessive users are not necessarily 'Internet addicts' as such. He states that, in many instances, a gambling addict, sex addict and so forth, are simply using the internet as a place to engage in their addictive behaviours. Hence, we cannot blame all people's addictions on the internet.

\subsection{Internet infidelity}

Another problematic online sexual activity is internet infidelity (see Whitty, 2003b, 2005; Whitty \& Carr, 2005, 2006). As Whitty (2003b, 2005) has argued, internet infidelity can be both emotional and sexual forms of betrayal. Internet infidelity is often construed as upsetting as offline infidelity (Whitty, 2003b). In one of Whitty's (2005) empirical studies on internet infidelity she found that the emotional betrayal was a greater concern for many individuals. Whitty and her colleagues have argued that people construe acts such as cybersex, hotchatting, emotional self-disclosure, and falling in love online as relationship transgressions because partners view this as time and desire being taken away from oneself and given to another love object. Moreover, the very act of keeping one's sexual activities a secret can lead to understandings that online activities ought to be deemed as unfaithful. Of course, one's internet infidelities might initiate online and progress offline. Moreover, there are webpages that have been set up to hook up people looking for an offline affair.

\subsection{Cyber-harassment and cyberstalking}


They are numerous recorded cases that describe how individuals have used the internet to stalk others and organisations. This is an obvious example of a very negative form of online relating. Perpetrators of online harassment and stalking include strangers, people close to one another (or were close to one another) and work colleagues. Whitty (2007a) has argued that the online environment could produce a greater number of stalkers and harasses than offline. One of the reasons for this is that given the absence of social cues on the internet people are given less feedback as to whether their behaviours are deemed appropriate or not and so people act out more than in an offline setting where they witness immediate feedback. Moreover, people can often be more easily located online. Arguably those addicted to online relationships and sex might also be more likely to cyberstalk (Whitty \& Joinson, in press).

\subsection{Online dating: getting it wrong}

As argued earlier in this paper, some of the negative encounters individuals experience on the internet might simply be explained by how they are using it to relate and present themselves. Whitty's (2007b, in press) work on online dating clearly illustrates this point. She found that those individuals who created profiles who exaggerated their looks, their status, or how much money they earned were far less likely to be successful at online dating. Moreover, those who wrote clichéd profiles were more likely to be over-looked by others on the site. In addition, individuals (especially men) who played the numbers game (i.e., sending out many emails to potential dates hoping one will respond) were viewed by others as not playing the online dating game by the rules. 


\section{Empirical support for positive experiences of online relationships}

While it is important to acknowledge what can go wrong when it comes to online relationships, this paper argues that much more goes right. In line with previous work (see Whitty \& Carr, 2006) it is argued here that cyberspace presents a unique opportunity for people to relate online - an experience that is sometimes difficult or impossible to achieve in any other medium.

\subsection{Real relationships on the Net}

There is ample evidence to support the view that people do make friends and initiate romantic relationships in cyberspace and often these relationships progress offline. For example, in the mid-90s Parks and Floyd (1996) found that two thirds (60.7\%) of their newsgroup sample had formed a personal relationship with someone they had met for the first time online. Of these, $7.9 \%$ stated that this was a romantic relationship. Utz (2000) found that $76.7 \%$ of the MUD users she surveyed reported forming a relationship online that developed offline, of which, $24.5 \%$ stated this was a romantic relationship. Whitty and Gavin (2001) found that individuals form real friendships in chat rooms and that some of these participants preferred that these relationships remain online. These days of course online dating sites and social networking sites continue to increase in popularity as a way to form new friendships, and seek out new romantic relationships and sexual encounters. In more recent research, Wolak, Mitchell, and Finkelhor (2003) found that $14 \%$ of youth reported close online friendships and $2 \%$ claimed to have established online romances. So we are left with little doubt that relationships do 
initiate online and progress successfully offline. Importantly, as highlighted above, these relationships are formed in numerous places online. The question that still remains is how psychologically healthy are these relationships? Are they worth our time or should we instead be spending more time in face-to-face encounters? This paper now attempts to address these questions.

4.2. Does the internet really cause people to become lonely?

Earlier in this paper, the classic HomeNet study was highlighted, which initially made the claim that online ties are 'weak' ties and are psychologically unhealthy because if people spend too much time online they start to feel more lonely. Kraut et al.’s (1998) Home- Net Study has, however, been widely criticised. One of the major criticisms made was that they only used 3-items from the UCLA to measure loneliness and their Cronbach's alpha of .54 was clearly poor (Grohol, 1998). Morahan-Martin (1999) argues that the sample size was too small and not randomly selected. Whitty and McLaughlin (2007) suggest that the results can be explained by considering how internet savvy the newbies in the Home- Net Study were. They believe that the participants were more likely in the initial stages to be ineffective users of the technology and the stress in trying to work out how to use this new technology might have caused them to become more psychologically distressed.

In the 3-year follow-up to the HomeNet study it was found that almost all of the previously reported negative effects had dissipated (Kraut et al., 2002). Instead, higher levels of internet use were positively correlated with measures of social involvement and psychological well-being. Whitty and McLaughlin (2007) 
argue that this is probably because the participants improved their internet skills and confidence over time and so in turn were able to develop more healthy online relationships.

Some researchers have argued that the internet is custom made for the lonely (Morahan- Martin, 1999). Rather than it causing loneliness some have suggested that the internet provides psychologically beneficial relationships that these individuals would have been deprived of had there not been an internet. Empirical research (detailed below) since the HomeNet studies seems to confirm the view that the internet can be an empowering space for lonely people. Moreover, we should be mindful that loneliness is not defined in terms of an individual's social network or number of friends, but rather as a subjective experience.

\subsection{Empowering space for the lonely?}

Whitty and McLaughlin (2007) found a relationship between lonely individuals and use of the internet for entertainment. Their study revealed that lonely individuals were more likely to use the internet compared to less lonely individuals for social activities, such as playing games and participating in chat rooms. Moreover, they found that the more lonely individuals in their sample were more likely to use the internet to obtain information about the entertainment world. These researchers argue that the lonely participants in their sample might have engaged in such activities as an escape from the outside world. Importantly, they acknowledge, however, that they were unable to ascertain whether lonely individuals were more likely to go to the internet for entertainment as a 
replacement for offline activities or if engaging in these activities caused them to become lonely. As the study also suggests, it might well be that it is those high in internet self-efficacy who benefit from some types of online encounters.

Amichai-Hamburger and Ben-Artzi (2003) tried to address the question of whether the internet causes loneliness or whether instead the lonely are more drawn to use the internet. More specifically they examined the relationship between extroversion, neuroticism, loneliness and internet use. A small sample of 85 Israel university students were given a battery of tests and asked about their internet use of a number of services (e.g., seeking information related to work or studies, joining discussion groups and visiting web-sites). As expected, the study found that extroverts and introverts use different services on the internet. Amichai-Hamburger and Ben-Artzi (2003, p. 77) claim that:

The unique contribution of this study is that is demonstrates not only that personality characteristics are related to differential Internet use, but also shows clearly the relationship between personality characteristics and loneliness as one important indicator of well-being. These results lead to a rejection of the negative generalization of the Internet made by Kraut et al. (1998).

In a more telling study conducted by Morahan-Martin and Schumacher (2003) 277 undergraduates were surveyed about their patterns of internet use. The study revealed that lonely individuals used the internet and email more than nonlonely individuals to make new friends and to interact with others with similar interests. In line with the 'disinhibition effect' (summarised earlier in this paper), lonely participants were more likely to prefer online communication than face-to- 
face communication and they felt more able to open up about themselves online. The more lonely individuals were also more likely to use the internet to modulate their negative moods. However, it is important to note that these same individuals reported that their internet usage interfered with their non-internet social activity often causing them to feel guilty. Morahan-Martin and Schumacher (2003, p. 669) argue that:

Taken together, this suggests a vicious circle whereby lonely individuals go online to fill social voids and emptiness in their life, but their online time creates voids their non-Internet social life and creates other real life problems. Thus, neither of the hypotheses about the direction of relationship between loneliness and Internet use is sufficient. Instead, the relationship may be bi-directional.

It is also noteworthy that the link between online relating and loneliness is not restricted to Western samples. More recent research examining a Japanese sample found support for the view that online friendships can be psychologically healthy (Ando \& Sakamoto, in press). Ando and Sakamoto (in press) in their study on 187 undergraduate students based in Tokyo and Kyoto found that the participants who rated themselves low in physical attractiveness benefited from having a large number of cyber-friends. These individuals were more likely to feel less lonely and socially anxious as a consequence of gaining these online friendships. This would confirm the current more popular view that 'weak ties' are psychologically beneficial. 


\subsection{A safe haven for the shy}

Researchers have argued that not only is cyberspace a potentially psychological beneficial space for lonely people, but equally it might be of benefit for the shy, socially inept, and socially anxious (Whitty and Carr, 2006a). For instance, it has been argued that cyberspace provides shy individuals a safe haven to cyberflirt (Whitty, 2003a, 2004; Whitty \& Carr, 2006a). Joinson's (2004) empirical work, in part, supports this theory. He found that individuals with low self-esteem showed a greater preference for email over face-to-face communication compared to individuals with high self esteem. Although he was not specifically studying shyness, Joinson comments that this finding "experimentally replicates the observation that shy people tend to benefit from computer-based dating systems, and anecdotal evidence that socially anxious people may be more likely to be 'pathological' Internet users than the more socially confident” (pp. 483-484).

Shy individuals do tend to flock to online dating sites to seek out romantic relationships. In a study by Scharlott and Christ (1995) it was found that "shier users were more likely to agree that Matchmaker allows them to explore new aspects of their personality" and that "seventy-four percent of the high-shyness users indicated that their main purpose in using Matchmaker was to find a romantic or sexual relationship, while only $46 \%$ of the low-shyness users answered that way" (Scharlott $\&$ Christ, 1995, p. 199). Given that the structure of online dating sites have changed since Scharlott and Christ collected their data Whitty and Buchanan (in press) decided to investigate the personality characteristics of online daters. These researchers found that although online dating sites these days require a more in-depth level of selfdisclosure and an insistence on providing visual information about oneself (in the form of photographs and video) that shy individuals are still very much drawn to 
online dating. These theorists argue that shy individuals still gravitate to online dating because it provides the social distance and a less real environment making it safer for individuals to initiate romantic relationships.

\subsection{Adolescents and the internet}

Both scholars and the media have been interested in the types of relationships adolescents form on the internet. Adolescent friendships are critical to examine given that friendships and intimacy increase in importance during late childhood and early adolescence (Buhrmester \& Furnman, 1987). Moreover, it has been found that close peer relationships correlate positively to adolescent selfesteem and psychological well-being. In contrast, problems with peer relationships can lead to depression and a negative self-image (Hartup, 1996).

Wolak et al. (2003) were interested in whether most adolescents form close friendships and romances online. In addition, they were interested in how often young people encounter unwanted communication and sexual solicitations online. They found that those adolescents with problems were more likely to develop close online relationships with other youth. This was especially the case for those who felt alienated from their parents.

In more recent research, Chou and Peng (2007) found from surveying 494 Taiwan adolescent high school students that most of their participants had 'netfriends'. Moreover, these adolescents felt they could be fairly open and honest with these friends. In the main they had positive attitudes in respect to the formation of online relationships. The types of perceived benefits of having a netfriend included, a greater chance of self-exposure and self-promotion, escape from life's pressures (e.g., homework, parental, school), more opportunities to experiment with their 'ideal self' and having fun. Interestingly, male students were more positive about their net-friends than female students.

\subsection{Exploring sexuality online}

Earlier in this paper the problems associated with being addicted to online sexual activities was discussed. However, engaging in online sexual acts is not a negative experience for all people and instead can be very liberating. Types of online sexual activities includes, downloading pornography, hot chatting, cybersex and incorporating the use of teledildonics. Hot chat is "when two or more individuals engage in discourses which move beyond light-hearted flirting" (Whitty \& Carr, 2006, p. 21). In contrast, cybersex is " generally understood to be synchronous communication in cyberspace where two or more individuals engage in discourses about sexual fantasies" (Whitty \& Carr, 2006, p. 21). Cybersex is not limited to textual exchanges but can also include video and the use of teledildonics.

Bulletin board systems (BBs) were a fairly popular space in the early days of the internet and many of these bulletin board systems were sexual in nature. Some BBs were especially designed for people to meet others who share their sexual interests and to live out their sexual desires online and/or offline. Wysocki (1998) interviewed participants using a BBs called 'The Pleasure Pit' and identified five main reasons for using sexually explicitly BBS, including anonymity, time constraints in one's personal life, the ability to share sexual 
fantasies with other people, the desire to participate in online sexual activity, and to find people with similar sexual interests to meet face-to-face. Overall, the results from her study suggest that engaging in online sexual activities can be liberating and empowering for many people, especially those with unusual fetishes who find it difficult to locate others offline with similar sexual interests.

Perhaps unsurprisingly, the internet is still a popular place for individuals with specialist fetishes. In more recent work, Wysocki and Thalken (2007) examined profiles constructed for an S\&M web site. Of the profiles randomly selected for the analysis, $37.5 \%$ identified as bisexual while $10 \%$ stated they were just curious. Many of the male photographs showed pictures of their erect penises and they were often stroking themselves. Women, in contrast, were mostly not in revealing shots and when they were they were either revealing their breasts or showing photographs bent over showing their buttocks. The profiles these two researchers examined demonstrated that individuals could be very explicit about what type of sex they were seeking. Like other places online, there was much evidence to suggest that individuals felt very uninhibited and free to express their sexuality - providing further support for the view that one can feel empowered and liberated in cyberspace.

\section{Conclusions}

The internet is constantly evolving which makes it a challenge for scholars to truly know the exact benefits and costs of relating on the internet. This paper presented theories which argue that the lack of social cues online leads to more impersonal communication. This arguably is less psychologically beneficial. In contrast, other theories were highlighted which also agree that there are costs to online relating, but that the many benefits should not be ignored. Moreover, that the internet provides unique opportunities compared to everyday face-to-face settings to relate to others. Sometimes relating online can be more personal and intimate (hyperpersonal) than relating face-to-face. Individuals can also learn new social skills online and potentially use these new found skills in their offline encounters. The evidence that relating online can have a negative impact on people's lives cannot be ignored. Spending time online might lead to greater loneliness, or increase people's chances of being stalked or even addicted to the internet. Nonetheless, it has been argued here that the benefits outweigh the costs. There is much evidence to support the view that people enjoy forming friendships, finding love and experiencing sexual encounters in cyberspace. Researchers need to spend more time learning about these positive experiences and how the internet might be best used to enhance people's well-being. 


\section{References}

Amichai-Hamburger, Y., and Ben-Artzi, E. (2003). Loneliness and Internet use. Computers in Human Behavior 19, 71-81.

Ando, R., and Sakamoto, A. (in press). The effect of cyber-friends on loneliness and social anxiety: Differences between high and low self-evaluated physical attractiveness groups Computers in Human Behavior.

Buhrmester, D., and Furnman, W. (1987). The development of companionship and intimacy Child Development 58, 1101-1113.

Cooper, A., Delmonico, D. L., and Burg, R. (2000). Cybersex users, abusers, and compulsives: New findings and implications Sexual Addiction \& Compulsivit, 7, 5-29.

Daft, R., and Lengel, R. (1986). Organizational information requirements, media richness and structural design Management Science, 32 (5), 554-571.

Daneback, K., Ross, M. K., and Månsson, S-A. (2006). Characteristics and behaviors of sexual compulsives who use the Internet for sexual purposes Sexual Addiction \& Compulsivity: The Journal of Treatment and Prevention, 13 (1), $53-67$.

Grohol, J. M. (1998). Response to the HomeNet study, PsychCentral. Retrieved October, 27, 2004. Available from <http://psychcentral.com/homenet.htm>.

Gross, E. F., Juvonen, J., and Gable, S. L. (2002). Internet use and well-being in adolescence Journal of Social Issues, 58 (1), 75-90.

Hartup, W. W. (1996). The company the keep: Friendships and their developmental significance Child Development, 67, 1-13. 
Hiltz, S., Johnson, M., and Turoff, M. (1986). Experiments in group decision making: Communication process and outcome in face-to-face versus computerized conferences Human Communication Research, 13, 225-252.

Joinson, A. N. (2001). Self-disclosure in computer-mediated communication: The role of self-awareness and visual anonymity European Journal of Social Psychology, 31, 177-192.

Joinson, A. N. (2004). Self-esteem, interpersonal risk, and preference for e-mail to face-to-face communication CyberPsychology \& Behavior, 7 (4), 479-485.

Kraut, R., Kiesler, S., Boneva, B., Cummings, J., Helgeson, V., and Crawford, A. (2002). Internet paradox revisited Journal of Social Issues, 58(1), 49-74.

Kraut, R., Lundmark, V., Patterson, M., Kiesler, S., Mukopadhyaya, T., and Scherlis, W. (1998). Internet paradox: A social technology that reduces social involvement and psychological well-being? American Psychologist 53, $1017-$ 1031.

Lea, M., and Spears, R. (1995). Love at first byte? Building personal relationships over computer networks. In J. T. Wood \& S.W. Duck (Eds.), Understudied relationships: Off the beaten track (pp. 197-233). Newbury Park, CA: Sage.

Lenhart, A. and Madden, M. (2007). Social Networking Websites and Teens: An Overview Pew Internet and American Life Project. Retrieved January, 10, 2007. Available from http://www.pewinternet.org/.

McKenna, K. Y.A., \& Bargh, J. A. (1998). Coming out in the age of internet: Identity 'de-marginalization' through virtual group participation. Journal of Personality and Social Psychology, 75, 681-694. 
McKenna, K. Y. A., \& Bargh, J. A. (2000). Plan 9 from cyberspace: The implications of the internet for personality and social psychology. Journal of Personality and Social Psychology, 4, 57-75.

McKenna, K. Y. A., Green, A. S., \& Gleason, M. E. J. (2002). Relationship formation on the Internet: What's the big attraction? Journal of Social Issues, 58, 9-31.

Morahan-Martin, J. (1999). The relationship between loneliness and Internet use and abuse Cyberpsychology \& Behavior, 2, 431-439.

Morahan-Martin, J., and Schumacher, P. (2003). Loneliness and social uses of the Internet Computers in Human Behavior, 19, 659-671.

Parks, M. R., and Floyd, K. (1996). Making friends in cyberspace Journal of Communication, 46, 80-97.

Parks, M. R., and Roberts, L. D. (1998). 'Making MOOsic': The development of personal relationships online and a comparison to their off-line counterparts Journal of Social and Personal Relationships, 15, 517-537.

Reicher, S. (1994). Social influence in the crowd: attitudinal and behavioural effects of de-individuation in conditions of high and low group salience British Journal of Social Psychology, 23, 341-350.

Schneider, J. P. (2000). Effects of cybersex addiction on the family. Results of a survey Sexual Addiction \& Compulsivity, 7, 31-58.

Short, J. A., Williams, E., and Christie, B. (1976). The social psychology of telecommunications. New York: John Wiley \& Sons.

Smahel, D., and Subrahmanyam, K. (2007). "Any girls want to chat press 911”: Partner selection in monitored and unmonitored teen chat rooms CyberPsychology \& Behavior, 10 (3), 346-353. 
Sproull, L., and Kiesler, S. (1986). Reducing social context cues: Electronic mail in organizational communication Management Science, 32, 1492-1512.

Suler, J. (2004). The online disinhibition effect. CyberPsychology \& Behavior, 7, 321- 326 .

Utz, S. (2000). Social information processing in MUDs: The development of friendships in virtual worlds. Journal of Online Behavior, 1 (1), Retrieved February 7, 2005 from http:// www.behavior.net/JOB/v1n1/utz.html

Walther, J. B. (1996). Computer-mediated communication: Impersonal, interpersonal and hyperpersonal interaction. Communication Research, 23, 3-43.

Walther, J. B., Slovacek, C., and Tidwell, L. (2001). Is a picture worth a thousand words? Photographic images in long-term and short-term computer-mediated communication Communication Research, 28, 105-134.

Whitty, M. T. (2002). Liar, Liar! An examination of how open, supportive and honest people are in Chat Rooms Computers in Human Behavior, 18 (4), 343-352.

Whitty, M. T. (2003a). Cyber-flirting: Playing at love on the Internet Theory and Psychology, 13 (3), 339-357.

Whitty, M. T. (2003b). Pushing the wrong buttons: Men's and women's attitudes towards online and offline infidelity CyberPsychology \& Behavior, 6 (6), 569579.

Whitty, M. T. (2004). Cyber-flirting: An examination of men's and women's flirting behaviour both offline and on the Internet Behaviour Change, 21 (2), 115-126.

Whitty, M. T. (2005). The 'Realness' of Cyber-cheating: Men and women's representations of unfaithful Internet relationships Social Science Computer Review, 23 (1), 57-67. 
Whitty, M. T. (2007). The art of selling one's self on an online dating site: The BAR Approach. In M. T. Whitty, A. J. Baker, \& J. A. Inman (Eds.), Online matchmaking. (pp. 57-69). Houndsmills: Palgrave Macmillan.

Whitty, M. T. (in press). Revealing the 'real' me, searching for the 'actual' you: Presentations of self on an internet dating site. Computers in Human Behavior. Whitty, M. T. and Buchanan, T. (in press). Looking for Love in so many Places: Characteristics of Online and Speed Daters. Interperona.

Whitty, M. T. and Carr, A. N. (2005). Taking the good with the bad: Applying Klein's work to further our understandings of cyber-cheating Journal of Couple and Relationship Therapy, 4(2/3), 103-115.

Whitty, M. T. and Carr, A. N. (2006a). Cyberspace romance: The psychology of online relationships. Basingstoke: Palgrave Macmillan.

Whitty, M. T. and Carr, A. N. (2006b). New Rules in the workplace: Applying objectrelations theory to explain problem Internet and email behavior in the workplace. Computers in Human Behavior, 22 (2), 235-250

Whitty, M., and Gavin, J. (2001). Age/sex/location: Uncovering the social cues in the development of online relationships CyberPsychology \& Behaviour, 4, 623630.

Whitty, M. T. and McLaughlin, D. (2007). Online recreation: The relationship between loneliness, internet self-efficacy and the use of the internet for entertainment purposes Computers in Human Behavior, 23 (3), 1435-1446.

Winnicott, D. W. (1971/1997). Playing and reality. London: Tavistock.

Wolak, J., Mitchell, K. J., and Finkelhor, D. (2003). Escaping or connecting? Characteristics of youth who form close online relationships Journal of Adolescence, 26, 105-119. 
Wysocki, D. K. (1998). Let your fingers to do the talking: Sex on an adult chat-line Sexualities, 1, 425-452.

Wysocki, D. K., and Thalken, J. (2007). Whips and chains? Content analysis of sadomasochism in internet personal advertisements. In M. T. Whitty, A. J. Baker, \& J. A. Inman (Eds.), Online matchmaking. (pp. 178-196).

Houndsmills: Palgrave Macmillan. 